\title{
On Diurnal Variation of Moto-excitability in Mimosa.
}

\author{
BY \\ J. C. BOSE, M.A., D.Sc., C.S.I. \\ Professor, Presidency College, Calcutta.
}

With seventeen Figures in the Text.

SEVERAL phenomena of daily periodicity are known, but the relations $\checkmark$ between the recurrent external changes and the resulting periodic variations are more or less obscure. As an example of this may be cited the periodic variation of growth. Here the daily periodicity exhibited by a plant is not only different in varying seasons, but it also differs in diverse species of plants. The complexity of the problem is very great, for not only are the direct effects of the changing environment to be taken into consideration, but also their unknown after-effects. Even in the case of direct effect, different factors, such as light, temperature, turgor, and so on, are undergoing independent variations; it may thus happen that their reactions may sometimes be concordant and at other times discordant. The nyctitropic movement of plants affords another example of daily periodicity. The fanciful name of 'sleep' is often given to the closure of the leaflets of certain plants at night. The question whether plants sleep or not may be put in the form of the definite inquiry: Is the plant equally excitable throughout day and night? If not, is there any definite period at which it practically loses its excitability? Is there, again, another period at which the plant wakes up, as it were, to a condition of maximum excitability?

In the course of my investigations on the irritability of Mimosa pudica, I became aware of the existence of such a daily periodicity; that is to say, the moto-excitability was found to be markedly diminished or even completely abolished at a certain definite period of the day; at another equally definite period, the excitability was observed to have attained its climax. The observations on the periodic variation of excitability appeared at first to be extremely puzzling. It might be thought, for example, that light would prove to be favourable for moto-excitability; in actual experiment the results apparently contradicted such a supposition: for the excitability of the plant was found much higher in the evening than in the morning. Favourable temperature, again, might be regarded as an important factor

[Annals of Botany, Vol. XXVII. No. CVIII. October, 1913.] 
for the enhancement of the moto-excitability; it was, nevertheless, found that though the excitatory response was only moderate at that period of night when the temperature was at its minimum, yet the excitability was altogether abolished at another period when the temperature was several degrees higher. The obscurities which surrounded the subject were only removed as a result of protracted investigation and comparison of continuous automatic records made by the plant itself during several months, beginning with winter and ending in summer.

The question whether a plant like Mimosa exhibits diurnal variation of excitability can be experimentally investigated by subjecting the plant at every hour of the day and night to a test-stimulus of uniform intensity, and

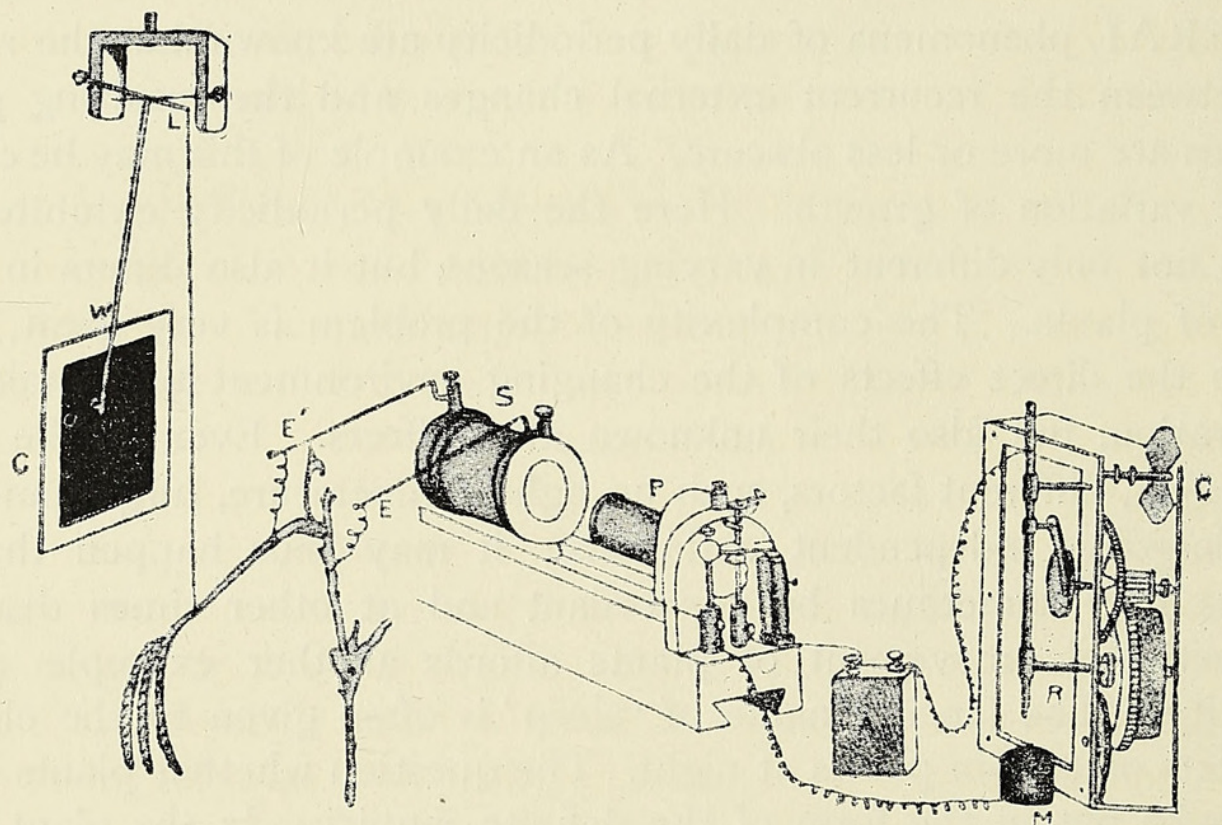

FIG. I. Diagrammatic representation of the complete apparatus for determination of diurnal variation of excitability. Petiole of Mimosa, attached by thread to one arm of lever L; writing index $\mathrm{W}$ traces on smoked glass plate $\mathrm{G}$ the responsive fall and recovery of leaf. $\mathrm{P}$, primary, and $\mathrm{s}$, secondary, of induction coil. Exciting induction passes through the plant by electrodes $\mathbf{E}, \mathrm{E}^{\prime}$. A, accumulator. C, clockwork for regulating duration of tetanizing shock. Primary circuit of coil completed by plunging rod $\mathrm{R}$ dipping into cup of mercury $\mathrm{M}$.

obtaining the corresponding mechanical responses. Under these circumstances the amplitude of response at any time will serve as a measure of the excitability of the plant at the particular time. Any periodic fluctuation of response will then demonstrate the periodic character of variation of excitability.

The investigation thus resolves itself into-

I. The successful construction of a Response Recorder which will automatically record the response of the plant to uniform periodic stimulalation at all hours of day or night;

2. The study of the effects of various external conditions on excitability ; 
3. The diurnal variation of excitability and its relation to the changes of external conditions.

I will first give a diagrammatic view of the different parts of the apparatus which I devised for this investigation. The leaf of Mimosa is attached to one arm of a light aluminium lever, L, by means of thread. At right angles to the lever is the writing index, $\mathrm{w}$, which traces on a smoked glass plate, allowed to fall at a definite rate by clockwork, the responsive movement of the leaf. Under a definite stimulus of electric shock the leaf falls down, pulling the lever $\mathrm{L}$, and moving the writer towards the left. The amplitude of this response-curve measures the intensity of excitation. The leaf re-erects itself after a time, the corresponding record exhibiting recovery. A second stimulus is applied after a definite interval, say an hour, and the corresponding response shows whether the excitability of the plant has remained constant or undergone any variation.

\section{I. (a) Uniform Periodic Stimulation.}

Electric mode of excitation. I find that one of the best methods of stimulating the plant is by means of tetanizing induction shock. The sensitiveness of Mimosa to electric stimulation is very great; the plant often responds to a shock which is quite imperceptible to a human subject. By the employment of a sliding induction coil, the intensity of the shock can be regulated with great accuracy; the secondary is gradually brought nearer the primary till a stimulus is found which is minimally effective. The intensity of stimulus actually employed is slightly higher than this, but within the sub-maximal range. When the testing stimulus is maintained constant and of sub-maximal intensity, then any variation of excitability is attended by a corresponding variation in the amplitude of response.

The exciting value of a tetanizing electric shock depends (I) on the intensity, (2) on the duration of shock. The intensity may be rendered uniform by placing the secondary at a fixed distance from the primary, and keeping the current in the primary circuit constant. The constancy of the primary circuit is secured by the employment of an accumulator or storage cell of definite electromotive force. It is far more difficult to secure the constant duration of the tetanizing shock in successive stimulations at intervals of, say, one hour during twenty-four hours. The duration of the induction shock given by the secondary coil depends on the length of time during which the primary circuit is completed in successive excitations. I have succeeded in overcoming the difficulty of securing uniformity of duration of shock by the employment of a special clockwork device.

The clockwork plunger. The alarum clock can be so arranged that a wheel is suddenly released and allowed to complete one rapid revolution at intervals of, say, one hour. There is a fan-governor by which the speed of the revolution can be regulated and maintained constant. This will specially 
be the case when the alarum spring is long and fully wound. The successions of short release, twenty-four times during the day, produce relatively little unwinding of the spring. On account of this and the presence of the fan-governor, the period of a single revolution of the wheel remains constant. By means of an eccentric the circular movement is converted into an up and down movement. The plunging rod $\mathrm{R}$ thus dips into a cup of mercury, $\mathrm{M}$, for a definite short interval (Fig. I) and is then lifted off. The duration of closure can be regulated by raising or lowering the cup of mercury. In practice the duration of tetanizing shock is about 0.2 second.

The same clock performs three distinct functions. The axis which revolves once in twelve hours has attached to it a wheel, and round this is wound a thread which allows the recording glass plate to fall through six inches in the course of twenty-four hours (Fig. 2). A spoke attached to the minute hand releases the alarum at regular and predetermined intervals of time, say once in an hour. The plunging rod $R$, actuated by the eccentric, causes a tetanizing shock of uniform intensity and duration to be given to the plant at specified times.

Constancy of resistance in the secondary circuit. In order that the testing electric stimulus shall remain uniform, another condition has to be fulfilled, namely, the maintenance of constancy of resistance in the secondary circuit, including the plant. Electric connexions have to be made with the latter by means of cloth moistened with dilute salt solution; drying of the salt solution, however, gives rise to a variation of resistance in the electrolytic contact. This difficulty is overcome by making the electrolytic resistance negligible compared to the resistance offered by the plant. Thin and flexible spirals of silver tinsel attached to the electrodes $\mathrm{E}, \mathrm{E}^{\prime}$ are tied round the petiole and the stem respectively. In order to secure better electric contact, a small strip of cloth moistened with dilute salt and glycerine is wound round the tinsel. As the resistance of contact is relatively small, and as drying is to a great extent retarded by glycerine, the total resistance of the secondary circuit undergoes practically no variation in the course of twenty-four hours. This will be seen from the following data: An experiment was commenced one day at I p.m., when the resistance offered by $8 \mathrm{~cm}$. length of stem and $2 \mathrm{~cm}$. length of petiole was found to be I.5 million ohms. After twenty-four hours' record, the resistance was measured the next day and was found unchanged. The fact that the stimulus remains perfectly uniform will be quite apparent when the records given in the course of this paper are examined in detail.

\section{I. (b) The Response Recorder.}

The amplitude of response affords, as we have seen, a measure of the excitability of the plant. In actual record friction of the writer against the glass surface becomes a source of error. This difficulty I have been able to 
overcome by the two independent devices, the Resonant Recorder ${ }^{1}$ and the Oscillating Recorder. In the former the writer is maintained by electric means in a state of continuous to and fro vibration, about ten times in a second. There is thus no continuous contact between the writer and the smoked glass surface, friction being thereby practically eliminated. The writer in this case taps a record, the successive dots occurring at intervals of $\cdot \mathrm{I}$ second. The responsive fall of the leaf is rapid, hence the successive dots in this part of the record are widely spaced; but the erection of the leaf during recovery takes place slowly, hence the recovery part of the curve appears continuous on account of the superposition of the successive dots. The advantage of the Resonant Recorder is that the curve exhibits both response and recovery. This apparatus is admirably suited for experiments which last for a few hours. There is, however, some drawback to its use in ex-

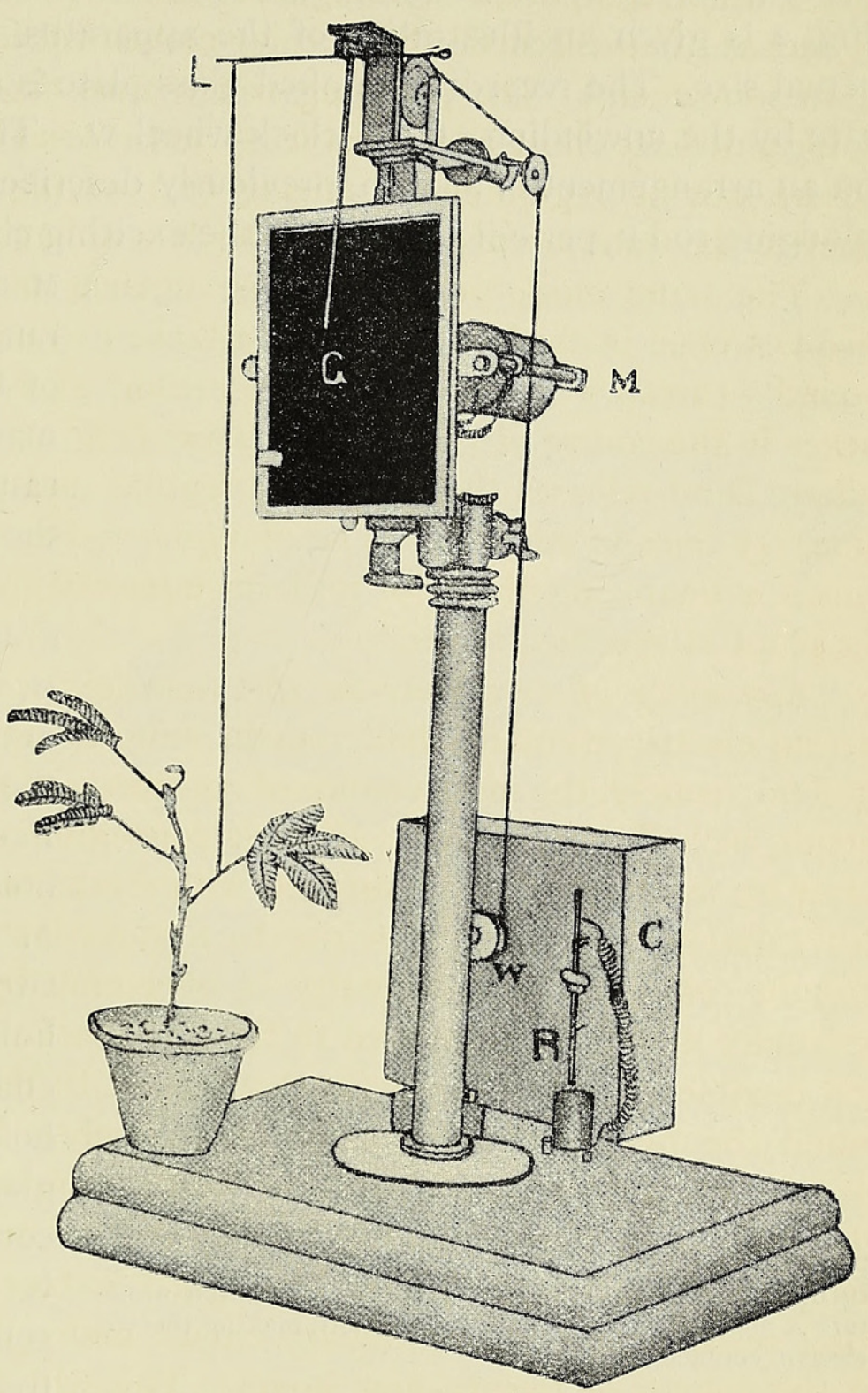

FIG. 2. The Oscillating Recorder. Petiole attached to one arm of lever $L$ by thread. The writer traces respon se-record on glass plate G, which falls at definite rate by unwinding of the clock wheel W. M, magnetic device for maintaining to and fro oscillation of recording plate. $\mathrm{R}$, plunging rod for periodic closure of exciting current. c, clockwork. periments which are continued for days together. This will be understood when we remember that for the maintenance of Io vibrations of the writer in a second, Io electric contacts have to be made; in other words, 36,000 intermittent electric

1 A complete account of the former is given in my paper 'On an Automatic Method of Investigation of the Velocity of Transmission of Excitation in Mimosa', read before the Royal Society, March 6, 1913 (Phil. Trans., B, No. 305, vol. 204). 
currents have to be kept up per hour. This necessitates the employment of an electric accumulator having a very large capacity.

In the Oscillating Recorder the recording plate itself moves to and fro, making intermittent contact with the writer, about once in a minute. In Fig. 2 is given an illustration of the apparatus, reduced to one-fourth the actual size. The recording smoked glass plate is allowed to fall at a definite rate by the unwinding of the clock wheel $\mathrm{w}$. The same clockwork, acting on an arrangement of alarum, previously described, causes, by means of the plunging rod $\mathrm{R}$, periodic closures of the exciting circuit for a definite duration.

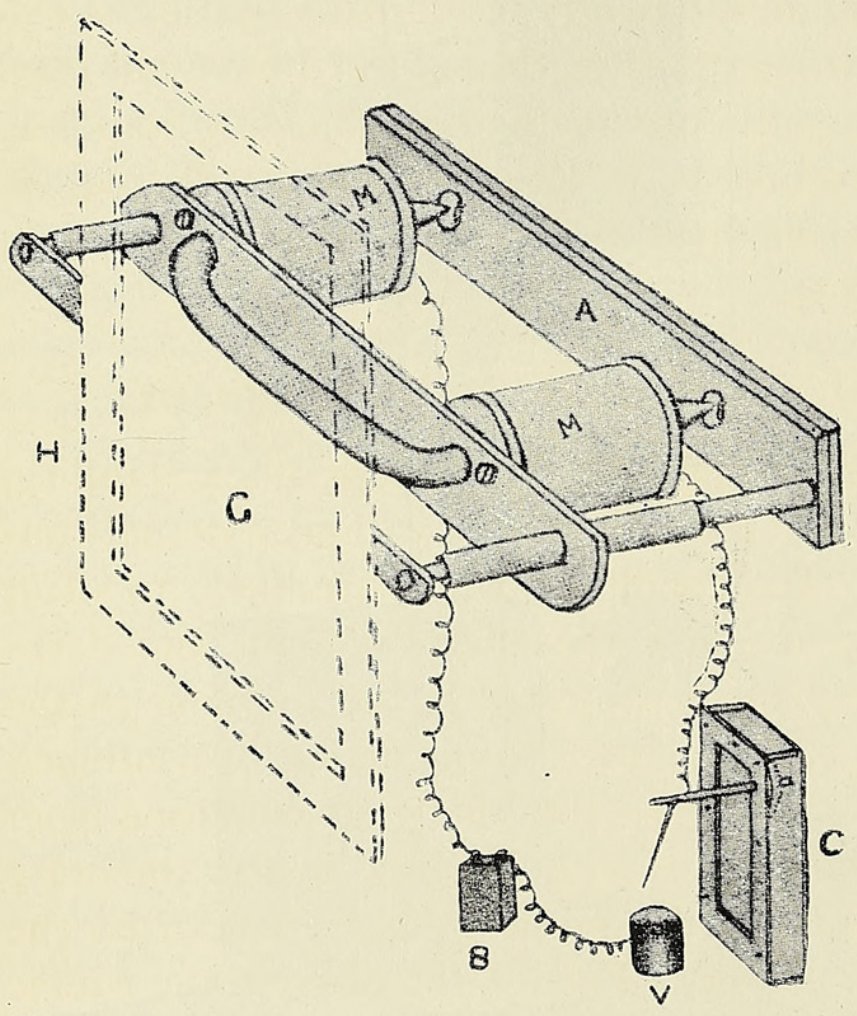

FIG. 3. The Oscillator. Electromagnet $\mathrm{M}, \mathrm{M}^{\prime}$, periodically magnetized by completion of electric current by clockwork c. Periodic attraction of soft iron armature A moves attached glass plate to left, making thereby electric contact with writer. writer. A clockwork $\mathrm{C}$ carries a rotating arm, which makes periodic contact with a pool of mercury contained in the vessel $\mathrm{v}$, once in a minute. On the completion of the electromagnetic circuit, the armature $\mathrm{A}$ is attracted, the recording glass plate being thereby moved to the left, making contact with the writer. The successive dots in the record thus take place at intervals of a minute. Only a moderate amount of electric current is thus consumed in maintaining the oscillation of the plate. A 4-volt storage cell of 20 amperes capacity is quite sufficient to work the apparatus for several days.

The responsive fall of the leaf of Mimosa is completed in the course of about two seconds. The leaf remains in the fallen or 'contracted' position 
for nearly fifteen seconds; it then begins to recover slowly. As the successive dots of the Oscillating Recorder are at intervals of a minute, the maximum fall of leaf is accomplished between two successive dots. The dotted response record here obtained exhibits the recovery from maximum fall under stimulation (cf. Fig. II). The recovery of the leaf in one minute is less than one-tenth the total amplitude of the fall, and is proportionately the same in all the response records. Hence the successive amplitudes of response curves that are recorded at different hours of the day afford us measures of the relative variations of excitability of the plant at different times. This enables us to demonstrate the reality of diurnal variation of excitability. In my experimental investigations on the subject $I$ have not been content to take my data from any particular method of obtaining response, but have employed both types of recorders, the Resonant and Oscillating. It will be shown that the results given by the different instruments are in complete agreement with each other.

\section{Effects of External Conditions on Excitability.}

Before giving the daily records exhibiting periodicity of excitability, I will give my experimental results on the influence of various external conditions in modifying excitability. The conditions which are likely to affect excitability and induce periodicity are, first, the effects of light and darkness : under natural conditions the plant is subjected in the morning to the changing condition from darkness to light; then to the action of continued light during the day; and in the evening to the changing condition from light to darkness. A second periodic factor is the change in the condition of turgidity, which is at its maximum in the morning, as evidenced by the characteristic erect position of the petiole. Finally, the plant in the course of day and night is subjected to a great variation of temperature. I will now describe the effects of these various factors on excitability. It should be mentioned here that the experiments were carried out about the middle of the day, when the excitability, generally speaking, is found to remain constant.

\section{(I) Effects of Light and Darkness.}

I have frequently noticed that a depression of excitability occurred when the sky was darkened by passing clouds. This is clearly seen in the following records obtained with the Resonant Recorder. Uniform submaximal stimuli had been applied to a specimen of Mimosa at intervals of fifteen minutes. The dotted up-line represents the responsive fall, and the continuous down-line, the slow recovery. The first four are the normal uniform responses (Fig. 4). The next three show the depressing effect of relative darkness due to cloudy weather. The sky cleared after forty-five minutes, and we notice the consequent restoration of normal excitability. 
Effect of sudden darkness and its continuation. In the next record (Fig. 5) is shown the immediate and continued action of darkness. The

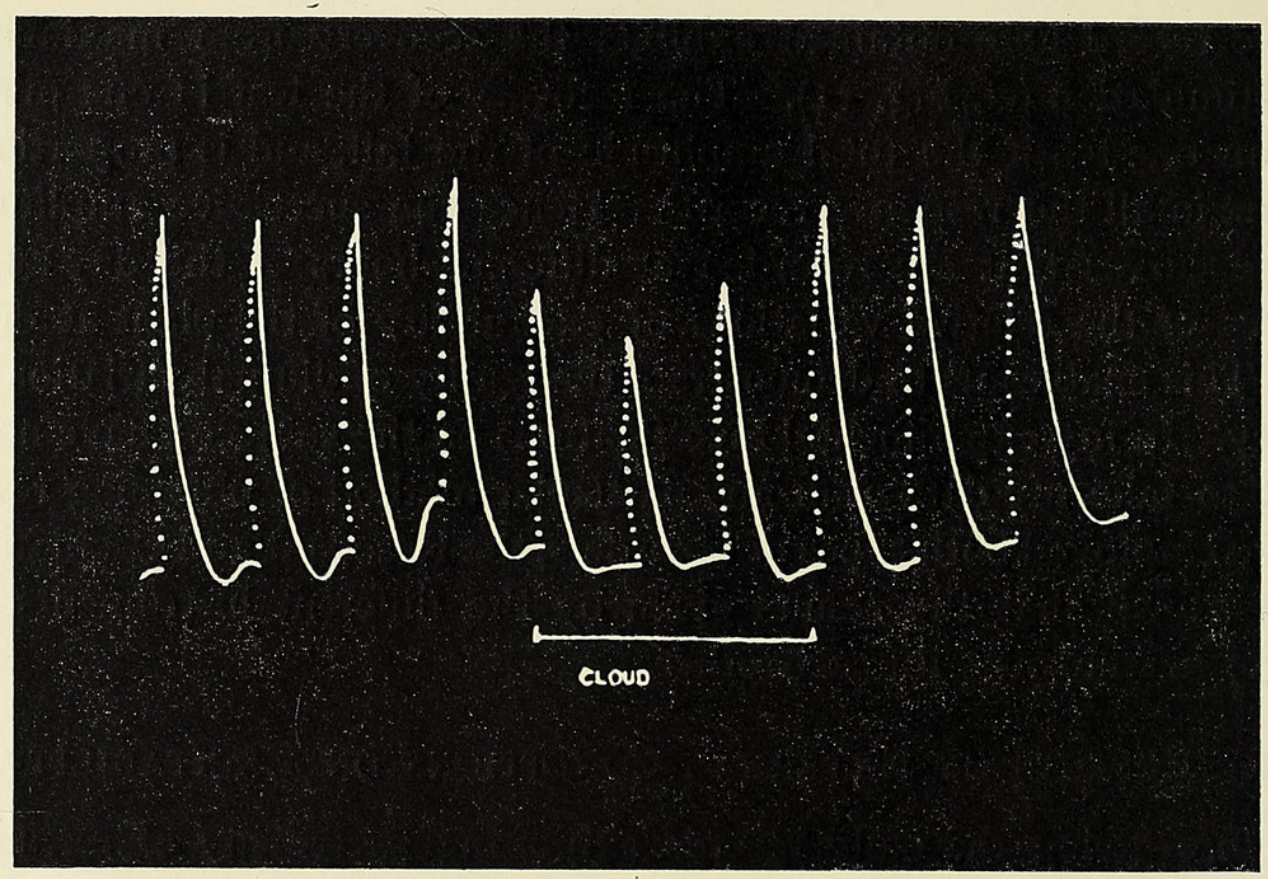

FIG. 4. Effect of cloud. Dotted up-curve indicates responsive fall, and continuous down-line exhibits slow recovery. First four responses normal; next three show depression due to diminution of light brought on by cloud, the duration of which is indicated by horizontal line below. Last three records show restcration of excitability brought on by clearing of sky. All records read from left to right.

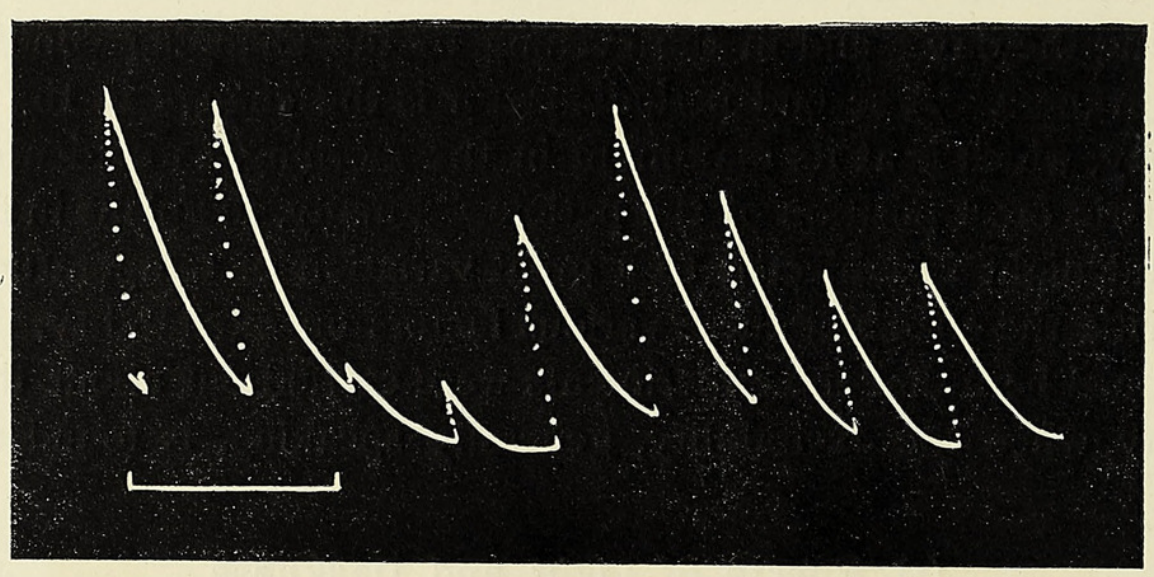

FIG. 5. Effect of sudden darkness. Plant subjected to sudden darkness beyond horizontal line seen below. First two responses normal. Note sudden depression of excitability, revival and final depression under continued darkness.

first two are the normal uniform responses in light. By means of screens, the plant was next subjected to sudden darkness; this brought about a marked depression of excitability. Subjection to sudden darkness thus acts as a stimulus inducing a marked but transient fall of excitability. Under the continuous action of darkness, however, the excitability is at first restored and then undergoes a persistent depression. 
Effect of transition from darkness to light. Here we have to deal first with the immediate effect of sudden transition, and then with the persistent effect of continuous light. In the record given in Fig. 6 the plant had been kept in the dark and the responses taken in the usual manner. It was then subjected to light; the sudden change from darkness to light acted as a stimulus, inducing a transient depression of excitability. In this connexion it is interesting to note that Godlewski found that in the phenomenon of growth, transition from darkness to light acted as a stimulus,

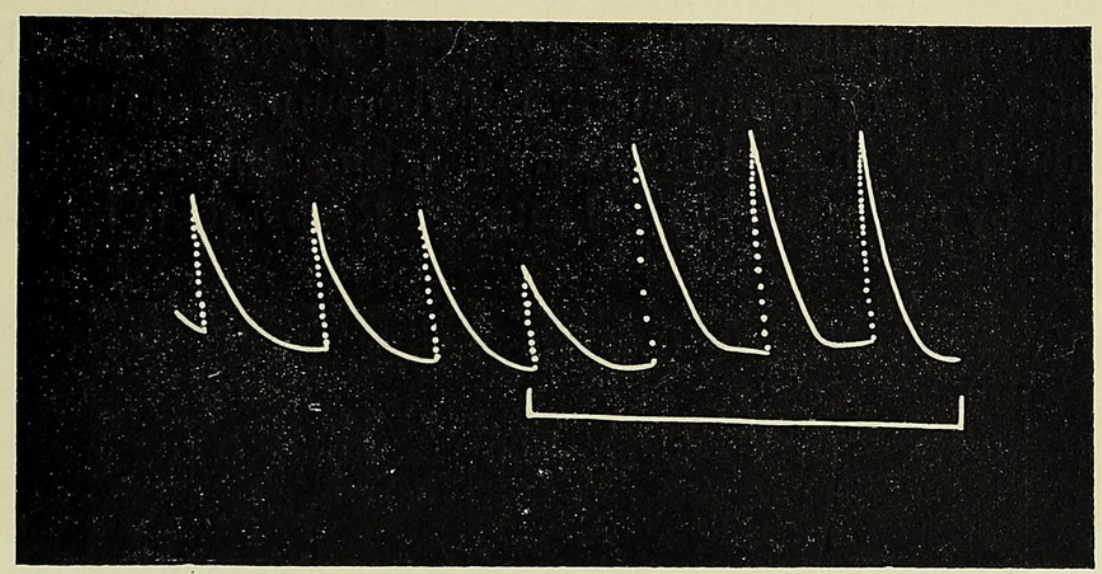

Fig. 6. Effect of change from darkness to light. The first three records are normal under darkness. Horizontal line below indicates exposure to light. Note preliminary depression followed by enhancement of excitability.

causing a transient decrease in the normal rate. The effect of continued light on Mimosa is an enhancement of excitability.

\section{(2) Effect of Enhanced Turgor.}

I have often found that the moto-excitability is depressed under excessive turgor. Thus the over-turgid leaf of Biophytum sensitivum does not exhibit any mechanical response on rainy days. The effect of excessive turgor on moto-excitability may be demonstrated in the case of Mimosa by

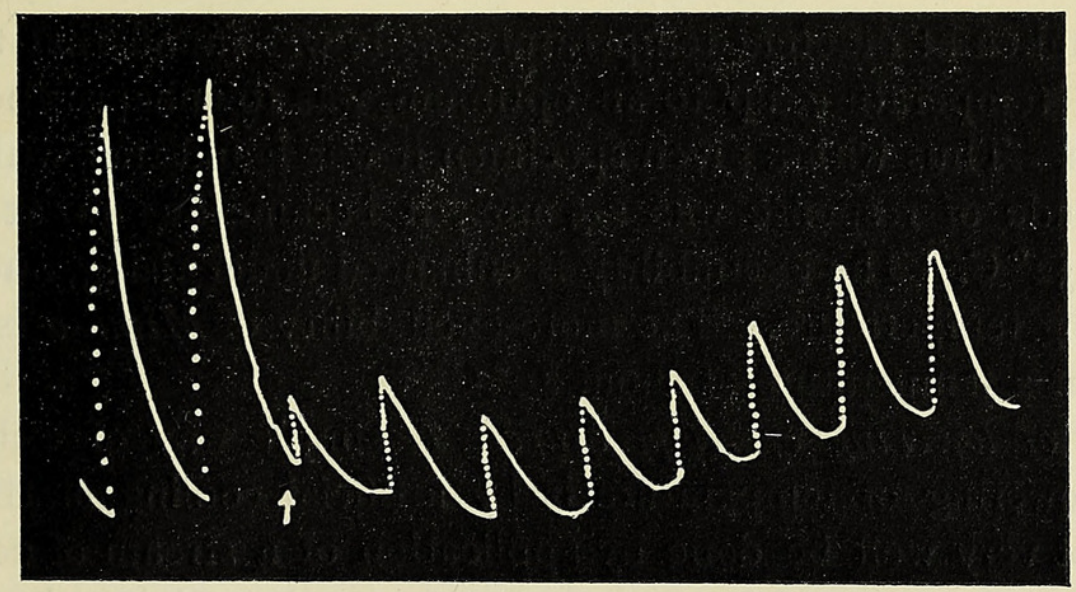

FIG. 7. Effect of enhanced turgor, artificially induced. First two responses normal. Application of water, at arrow, induces depression of moto-excitability. 
allowing its main pulvinus to absorb water. The result is seen in the next record (Fig. 7), where water was applied on the pulvinus after the second response. It is seen how a depression of moto-excitability results from excessive turgor brought on by absorption of water. In such cases, however, the plant may accommodate itself to the abnormal condition and gradually regain its normal excitability in the course of several hours.

\section{(3) Influence of Temperature.}

The moto-excitability of the pulvinus of Mimosa is greatly modified under the influence of temperature. For the purpose of this investigation I enclosed the plant in a glass chamber, raising the temperature to the desired degree by means of electric heating. Responses to identical stimuli

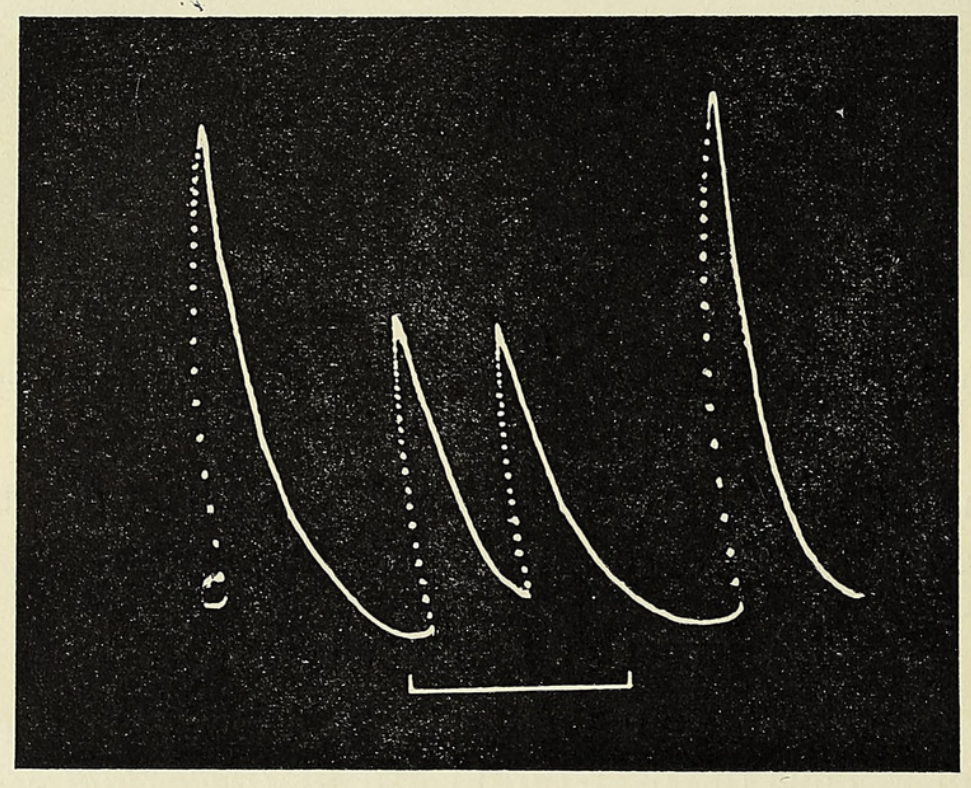

FIG. 8. Effect of moderate conling during a period shown by horizontal line below. Moderate depression followed by quick restoration.

were then taken at different temperatures. It was found that the effect of heightened temperature, up to an optimum, was to enhance the amplitude of response. Thus with a given specimen it was found that while at $22^{\circ} \mathrm{C}$. the amplitude of response was $2.5 \mathrm{~mm}$., it became $22 \mathrm{~mm}$. at $27^{\circ} \mathrm{C}$., and $52 \mathrm{~mm}$. at $32^{\circ} \mathrm{C}$. The excitability is enhanced under rising, and depressed under falling temperature. The moto-excitability of Mimosa is practically abolished at a temperature of about $19^{\circ} \mathrm{C}$.

Effect of lowering of temperature. A simple way of exhibiting the effect of lowering of temperature is by artificial cooling of the pulvinus. This cannot very well be done by application of a stream of cooled water, because, as we have seen, absorption of water by the pulvinus is attended by a loss of excitability: glycerine has, however, no such drawback. This fluid 
at ordinary temperature was first applied on the pulvinus, and records were taken in the usual manner. Cooled glycerine was then applied and the record taken once more; the results are seen in Figs. 8 and 9. In the former, the first response was normal at the temperature of the room, which was $32{ }^{\circ} \mathrm{C}$; the next two exhibit depression of excitability under moderate cooling; the duration of application of moderately cooled glycerine is here indicated by the horizontal line below. On the cessation of application, the normal temperature was quickly restored, with the restoration of normal excitability.

In the next record (Fig. 9) is shown the effect of a more intense cold. It will be noticed that the first effect was a depression, and subsequently, a complete abolition of excitability. The thick dots in the record represent applications of stimulus which proved ineffective. It will also be noticed

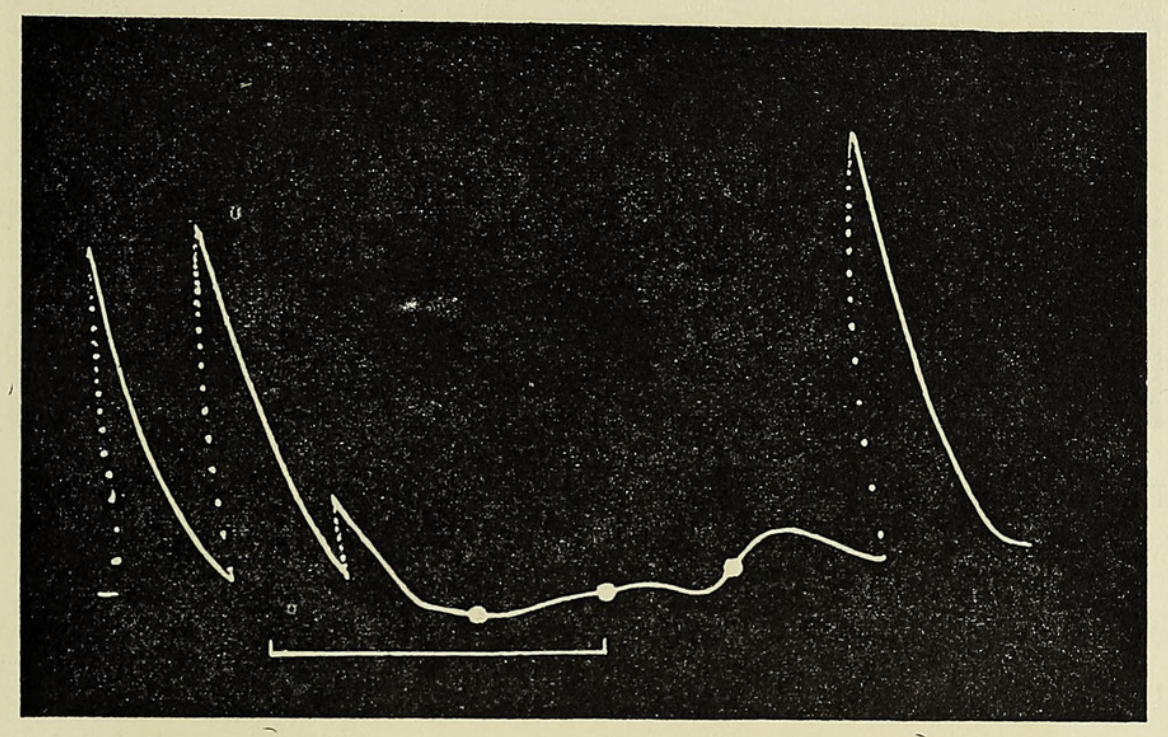

FIG. 9. Effect of application of more intense cold. Note sudden depression followed by abolition of excitability, also persistent after-effect.

that even on the cessation of cooling, and the return of the tissue to normal temperature, the induced abolition of excitability persisted as an after-effect for a considerable time. I have likewise found that the after-effect of cold in abolishing the conduction of excitation is also very persistent. These experiments show that the variations of excitability in the plant often lag considerably behind the external changes which induce them.

Effect of high temperature. It has been shown that the moto-excitability is enhanced by rising temperature; there is, however, an optimum temperature above which the excitability undergoes a depression. This is seen in the following record (Fig. IO), where the normal response at $32^{\circ} \mathrm{C}$. was depressed on raising the temperature to $42^{\circ} \mathrm{C}$.; the excitability was, however, restored when the plant was allowed to regain the former temperature. 
I may now briefly recapitulate some of the important results : darkness depresses, and light exalts the moto-excitability. Excessive turgor depresses motility. Still more marked is the effect of temperature. Lowering of temperature depresses and finally abolishes the moto-excitability: rise of temperature enhances it up to an optimum temperature, but beyond this point the excitability undergoes depression. The change in excitability

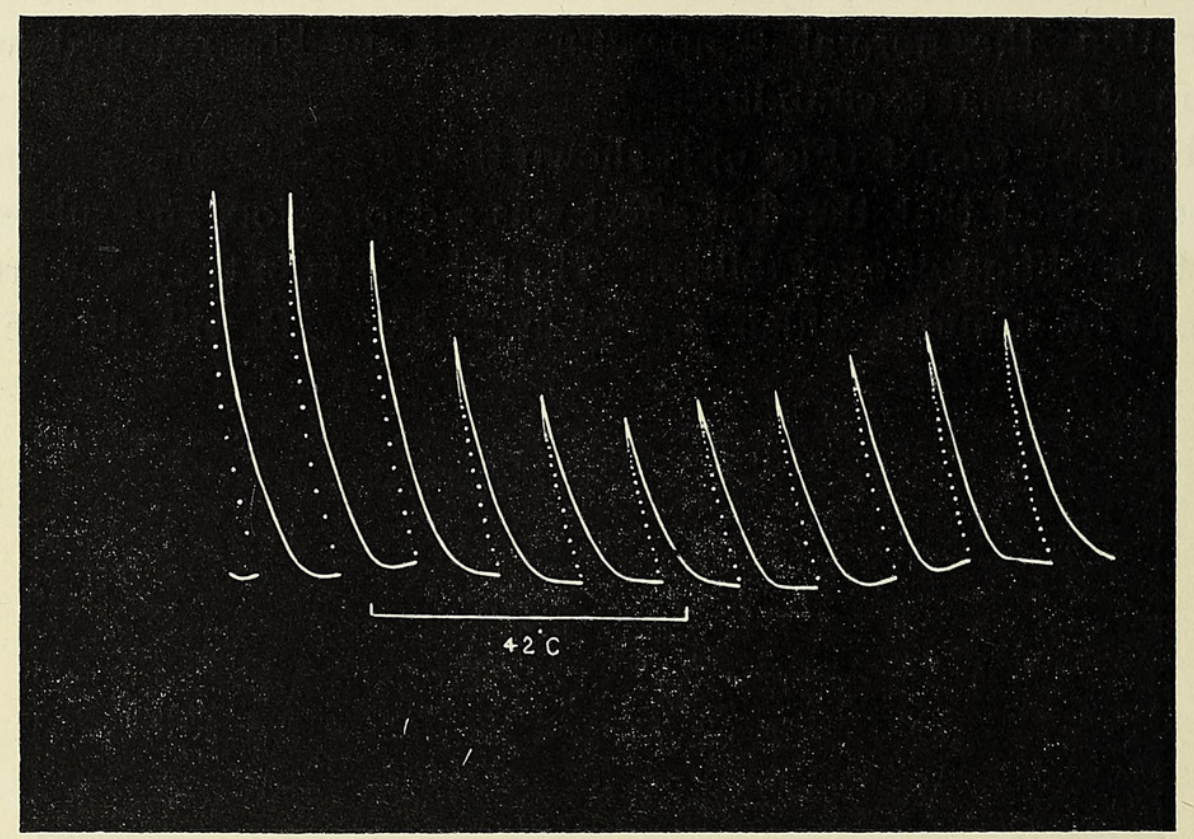

FIG. IO. Effect of temperature above optimum. Note depression of excitability induced by high temperature, and gradual restoration on return to normal.

induced by the variation of external condition is not immediate; the induced effect, generally speaking, lags behind the inducing cause.

\section{DiURnal VARIation of Excitability.}

I will now give automatic records of responses taken once every hour for twenty-four hours. They prove conclusively the diurnal variation of excitability in Mimosa. After studying in detail the variations characteristic of particular times of the day, I will endeavour to correlate them with the effects brought on by the periodic changes of the environment.

As a typical example I will first give a record obtained in the month of February, that is, say in spring. From this it will not be difficult to follow the variations which take place earlier in winter or later in summer.

The record given in Fig. II was commenced at 5 p.m., and continued to the same hour next day. The first thing noticeable is the periodic displacement of the base-line. This is due to the nyctitropic movements of the leaf. It should be remembered that the up movement of the leaf is represented by down-curve, and vice versa. After the maximum fall of the leaf, which in this case was attained at 9 p.m., there followed 
a reverse movement : the highest erection, indicative of maximum turgor, was reached at 6 a.m. The leaf then fell slowly and reached a middle position at noon. The extent of the nyctitropic movement varies in individual cases; in some it is slight, in others very large. The erectile movement began, as stated before, at about 9 p.m.; in some cases, however, it may occur as early as 6 p.m.

In following the characteristic variations of response, occurring throughout the day, we find that while they are practically uniform between the hours of 5 and 7 p.m., a continuous decline is manifested after setting in of darkness $(6$ p.m.); the fall of excitability continues even after sunrise

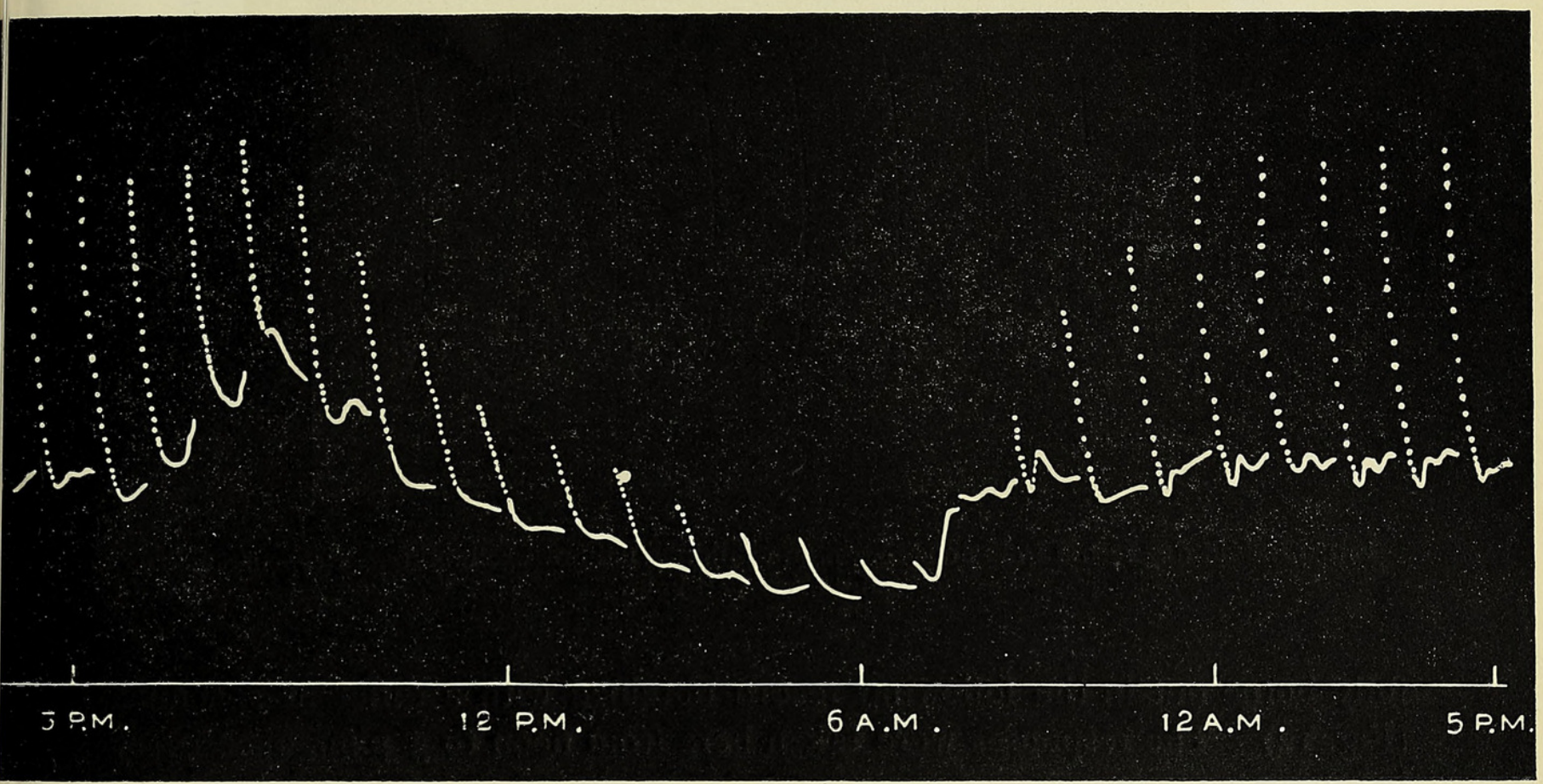

FIG. II. Record for twenty-four hours, exhibiting diurnal variation of excitability (spring specimen). The displacements of base-line are due to nyctitropic movements.

(6.30 a.m.), response being practically abolished at 9 a.m. The excitability is then gradually restored in a staircase manner, the maximum being reached after 12 noon. After attaining this, the excitability remains constant till the evening. It will be noticed that the amplitude of response at $5 \mathrm{p} . \mathrm{m}$. on the second day was the same as the corresponding response on the previous day.

The results of this and numerous other records taken in spring may be summarized as :

I. The maximum excitability of Mimosa is attained at about I p.m., and remains constant till the evening.

2. The excitability, generally speaking, undergoes a continuous decline from evening to morning, the response being practically abolished at or about 9 a.m. 
3. From 8 a.m. to $\mathrm{I} 2$ noon, the excitability is gradually enhanced in a staircase manner, till the maximum excitability is reached near I p.m.

I have obtained numerous records in support of these conclusions, some of which are reproduced in the following figures. In these cases responses to uniform stimuli at intervals of half an hour were taken at different parts of the day, the recorder employed being of the Resonant type.

Mid-day record. The record of daily periodicity previously given shows that the excitability reaches its maximum after I 2 noon, and that it remains constant at the maximum value for several hours. This fact is

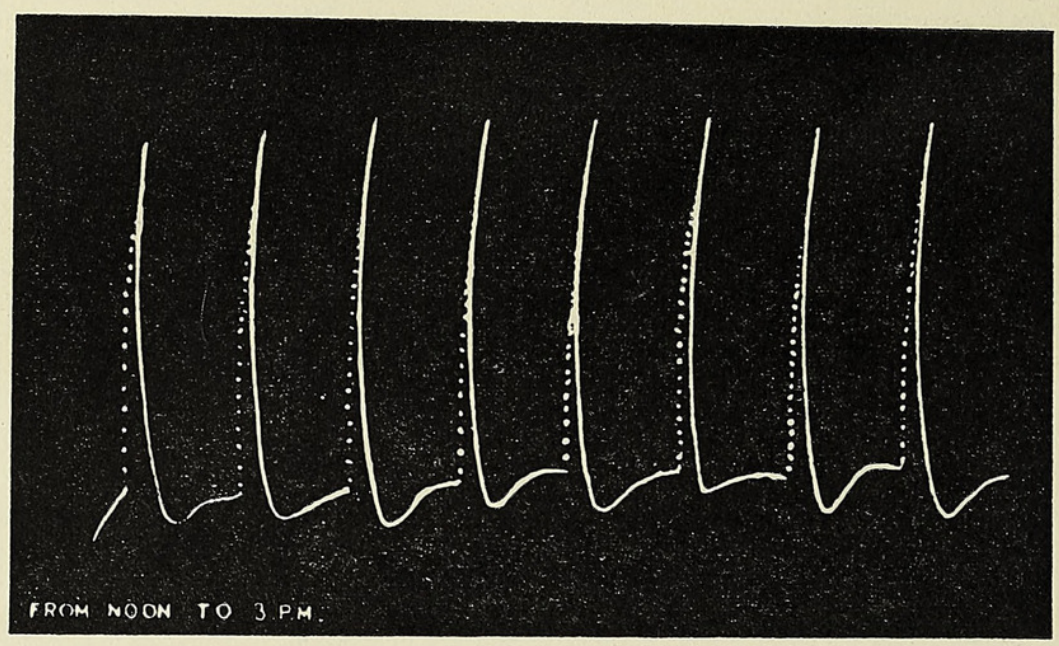

FIG. I 2. Mid-day record from noon to 3 p.m. exhibiting uniform excitability. Responses taken once every half-hour.

fully borne out in the following record obtained with a different specimen (Fig. I2). The responses were taken here from noon to 3 p.m., once every half-hour.

Evening record. The record given in Fig. I I shows that the amplitude of response falls continuously after 6 p.m. It might be thought that the diminished amplitude in the first part may be due to the natural nyctitropic fall of the leaf. The range of the pulvinar movement being limited, it is clear that the extent of the responsive fall must become smaller on account of the natural fall of the leaf during the first part of the night. That this is not the whole explanation of the decline of response in the evening will be clear from certain facts which I will presently adduce. It was stated that the leaf of Mimosa exhibits nyctitropic fall from 6 to 9 p.m., after which there is a reverse movement of erection. In certain specimens, however, the erectile movement commenced as early as $6 \mathrm{p} . \mathrm{m}$. It is obvious that in these latter cases diminution of amplitude of response cannot be due to the reduction of the range of movement of the leaf. In Fig. I 3 is given a series of records from 6 to Io p.m. obtained with a leaf in which erectile movement had commenced early in the evening. Though the fullest range of 
responsive movement was in this case available, yet the amplitude of successive responses is seen to undergo continuous diminution.

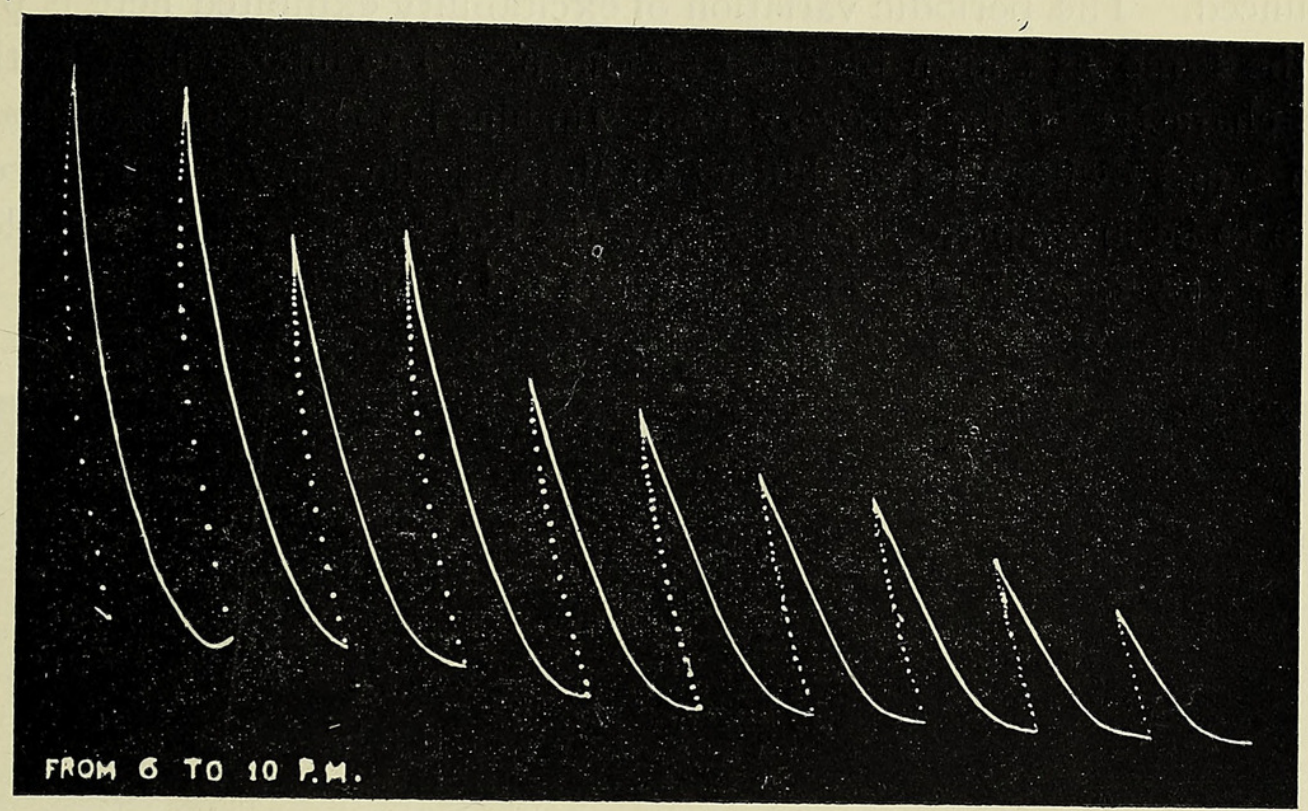

Fig. I3. Evening record from 6 to Io p.m., showing gradual depression of excitability.

Record in the morning. The excitability is, as we have seen, nearly abolished about 8 or 9 a.m., after which there is a gradual restoration. This gradual enhancement of excitability to a maximum in the course of the forenoon is seen well illustrated in the following record (Fig. I4).

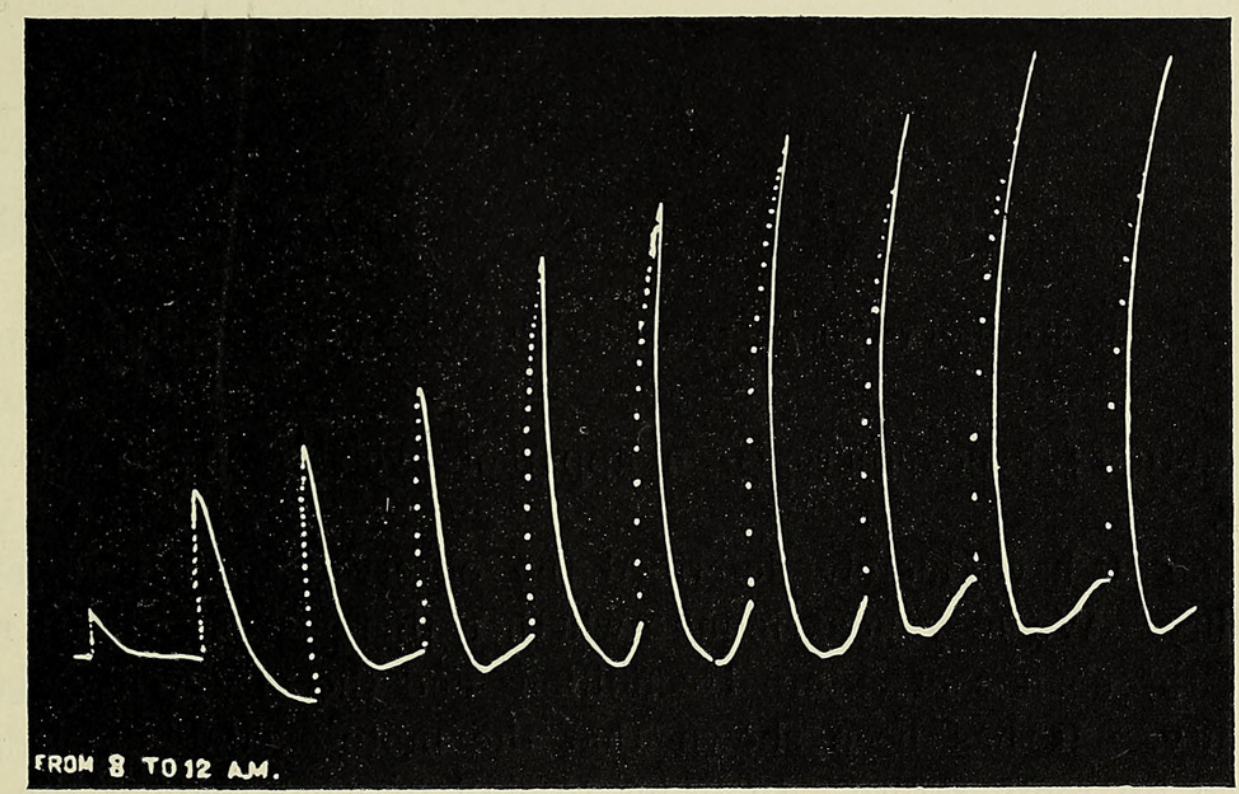

Fig. 14. Morning record from 8 a.m. to I 2 noon, exhibiting gradual enhancement of excitability.

The record of daily periodicity given in Fig. II may be regarded as a typical example. Modifications may, however, be observed which are $3 \mathrm{G}$ 
traceable to individual peculiarities. As an example of this, I give a record (Fig. I5) obtained with a specimen in which nyctitropic movement was very pronounced. The periodic variation of excitability exhibited here is practically the same as shown by other specimens. The interesting variation is in the character of the recovery from stimulus; the leaf was falling from 6 to 9 p.m.; owing to the shifting of the base-line upwards the recovery appears to be incomplete. After 9 p.m. the leaf was erected, at first slowly, then at a very rapid rate. The consequent fall of the base-line late at night

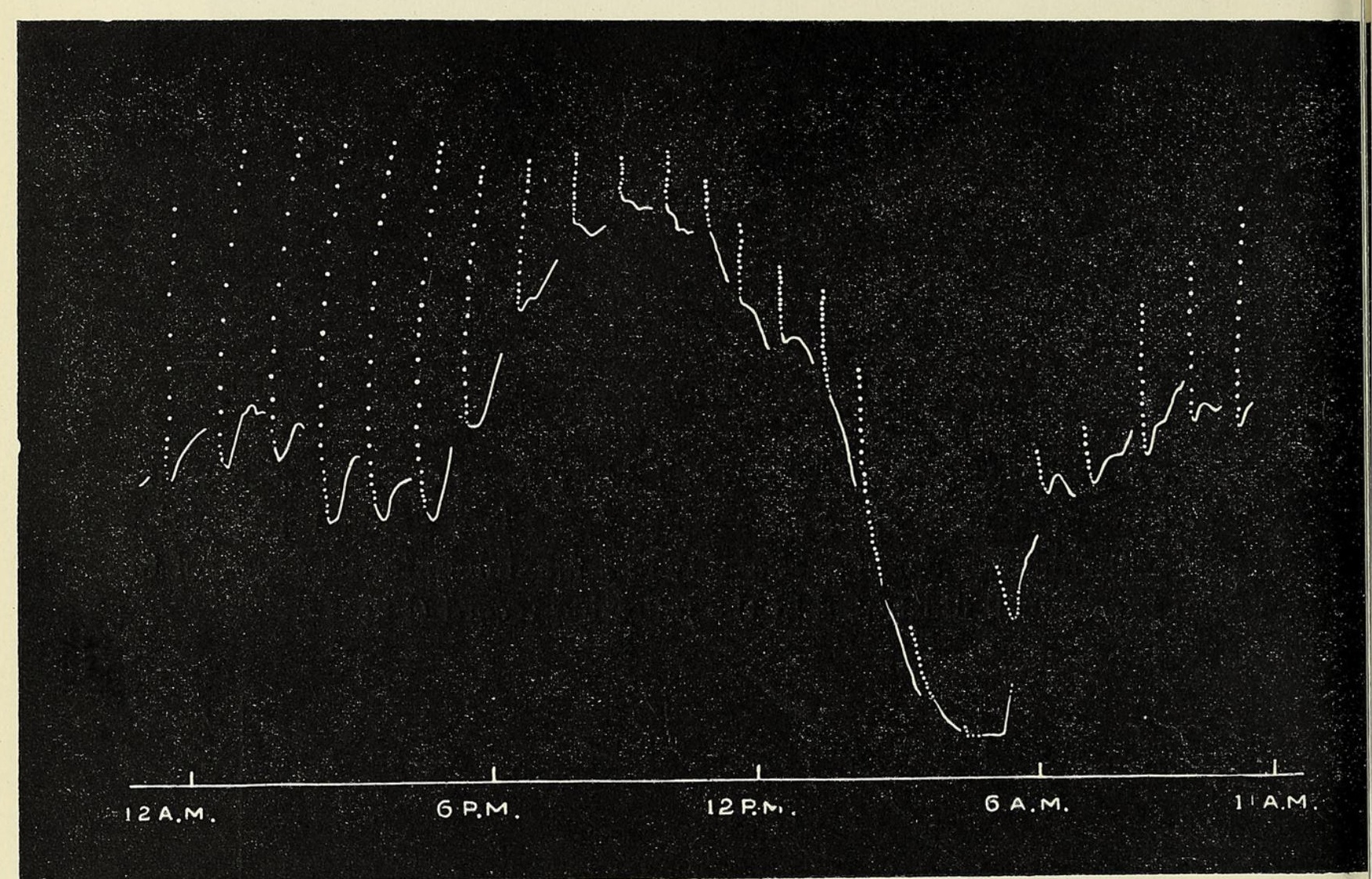

FIG. I5. Record of diurnal variation of excitability : it exhibits marked nyctitropic movement.

is very abrupt; hence there is an apparent overshooting in the line of recovery.

So far I have merely described the observed diurnal variation of excitability. We may next inquire whether there is any causal relation between the change of external conditions and the observed variation of excitability. It has been shown that the moto-excitability is greatly influenced by temperature. In order to find in what manner the diurnal variation of excitability was influenced by the daily variation of temperature, I took special care to secure by means of the thermograph a continuous record of temperature variations. The table which follows shows the relation between the hours of the day, temperature, and amplitude of response, in 
that particular case whose diurnal variation of excitability is given in Fig. II.

\section{TABLE I.}

Showing the relation between hour of the day, temperature, and excitability. (Spring specimen.)

\begin{tabular}{|c|c|c|c|c|c|c|}
\hline $\begin{array}{c}\text { Hours of } \\
\text { day. }\end{array}$ & Temperature. & $\begin{array}{c}\text { Amplitude of } \\
\text { response. }\end{array}$ & $\begin{array}{c}\text { Hours of } \\
\text { day. }\end{array}$ & Temperature. & $\begin{array}{l}\text { Ampli } \\
\text { resp }\end{array}$ & $\begin{array}{l}\text { tude of } \\
\text { onse. }\end{array}$ \\
\hline $\begin{array}{l}5 \mathrm{p} . \mathrm{m} . \\
6,,\end{array}$ & $\begin{array}{l}28^{\circ} \quad \mathrm{C} . \\
25 \cdot 5^{\circ},\end{array}$ & $\begin{array}{lc}28 & \mathrm{~mm} \\
28 & \end{array}$ & ${ }_{6}^{5}$ a.m. & $\begin{array}{l}20^{\circ} \mathrm{C} . \\
20 \cdot 5^{\circ},\end{array}$ & $\begin{array}{l}5 \\
4^{\cdot} \cdot 2\end{array}$ & mm. \\
\hline 7, & $24.5^{\circ}$ & $27 \quad$ & 72 & $21^{\circ}$, & $3 \cdot 5$ & , \\
\hline 8, & $23^{\circ} \quad$, & 23.5, & 8, & $22^{\circ}$ & $2 \cdot 5$ & , \\
\hline 9 & $22^{\circ} \quad$, & $2 \mathrm{I} \cdot 5$, & 9, & $24^{\circ}$ & o & , \\
\hline IO , & $2 \mathrm{I}^{\circ},$, & I 8 & I0 ,, & $26^{\circ} \quad$, & 6 & , \\
\hline I I , , & $20 \cdot 5^{\circ}$, & I 5 & I I ,, & $26 \cdot 5^{\circ}$, & I 5.5 & , \\
\hline I 2 , & $20^{\circ} \quad$, & I 3 & I 2, & $28^{\circ} \quad$, & 22.5 & , \\
\hline I a.m. & $20^{\circ}$ & 10 & I p.m. & $28^{\circ}$, & 26 & , \\
\hline 2, & $20^{\circ}$ & 8 & & $28 \cdot 5^{\circ}$, & 28 & ", \\
\hline , & $20^{\circ}$, & $7 \cdot 5$ & ," & $28 \cdot 5^{\circ}$, & 28 & $"$ \\
\hline$"$ & $19.5^{\circ}$, & $6 \quad$, & , & $29^{\circ} \quad$, & 28 & , \\
\hline
\end{tabular}

From the data given in the table, two curves have been obtained. One of these shows the relation between the hours of the day and temperature; the other exhibits the relation between the hours of the day and the excitability as gauged by the amplitude of response (Fig. I6). It will be seen that there is, broadly speaking, a marked resemblance between the two curves, which, however, are not coincident. The minimum temperature, for example, was attained at about 4 a.m., but the excitability was not reduced to a minimum till several hours later. This want of coincidence is probably due to the following causes :

I. The influence of temperature on excitability is, as has been shown, not immediate. Hence there is a lag between the cause and the effect induced.

2. There are, again, other factors, such as variations of light and turgor, which affect the excitability. But the period of maximum effect induced by any of these does not necessarily coincide with that induced by temperature.

We may now discuss in greater detail the diurnal variation of excitability in Mimosa, taking the typical case, the record of which is given in Fig. II. The temperature here is seen to remain almost constant, and at an optimum, from I to $5 \mathrm{p} . \mathrm{m}$., the condition of light is also favourable. Hence the excitability is found to be constant, and at its maximum, between these hours. The temperature begins to fall in the evening after 6 p.m., and there is, in addition, the depressing action of gathering darkness. Owing to the time-lag, the fall of excitability does not commence immediately at 6 p.m., but an hour afterwards, and continues till the next morning. Various factors, moreover, conspire about this time to bring about a maximum depression of excitability. First, we have the cumulative effect of twelve hours' darkness; secondly, there is a diminution of moto-excitability 
due to excess of turgor, the latter attaining its maximum at about 7 a.m. And, lastly, we have the depressing effect of cold, the temperature minimum occurring at $4 \mathrm{a} . \mathrm{m}$. On account of the combined effects of these various factors, and the phenomenon of lag, the period of minimum excitability is in general reached about 9 a.m. In certain other cases this may occur

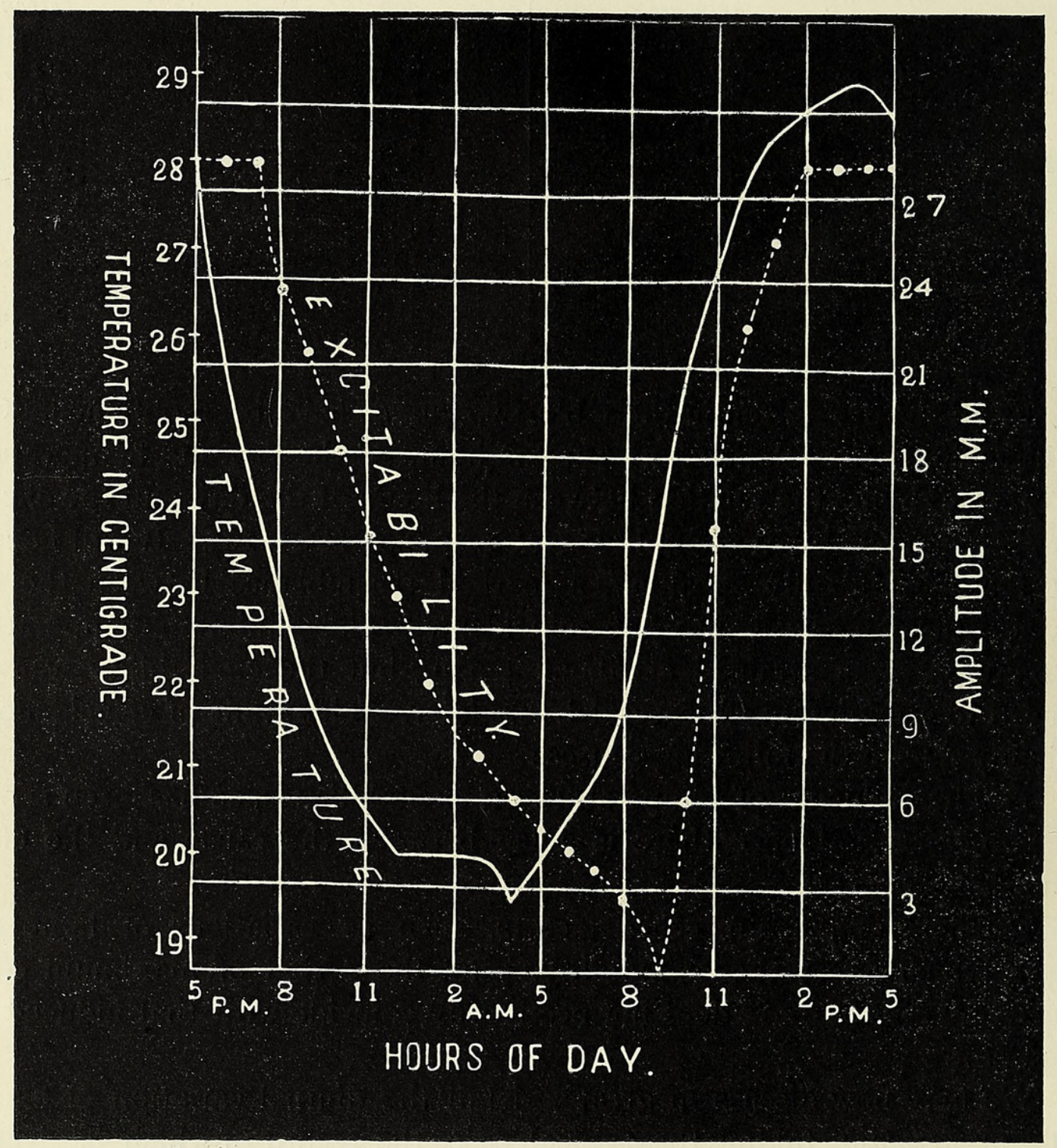

FIG. I6. The continuous curve shows the relation between the hour of the day and temperature. The dotted curve exhibits relation between the hour of the day and excitability.

earlier. After the attainment of this minimum, the excitability is gradually and continuously increased, under the action of light and of rising temperature. In the present case the highest temperature, $28^{\circ} \mathrm{C}$., was reached at noon, and the maximum excitability attained an hour afterwards.

It was said that temperature exerted a predominant influence in inducing variation of excitability. We may therefore expect that the diurnal period would be modified in a certain way according to the season. 
In winter the night temperature falls very low; hence the depression of excitability is correspondingly great, and results in the complete abolition of excitability. The after-effect of intense cold is seen in the condition of inexcitability persisting for a very long period in the morning. In summer the prevailing high temperature modifies the diurnal periodicity in a different manner. When the night is warm, the fall of excitability is slight. In the day, on the other hand, the temperature may rise above the optimum, bringing about a depression. In such a case the excitability in the earlier part of the evening may actually be greater than in the middle of the day. These modifications are shown in a very interesting way in the following record (Fig. I7) taken at the end of April. The temperature of Calcutta at this

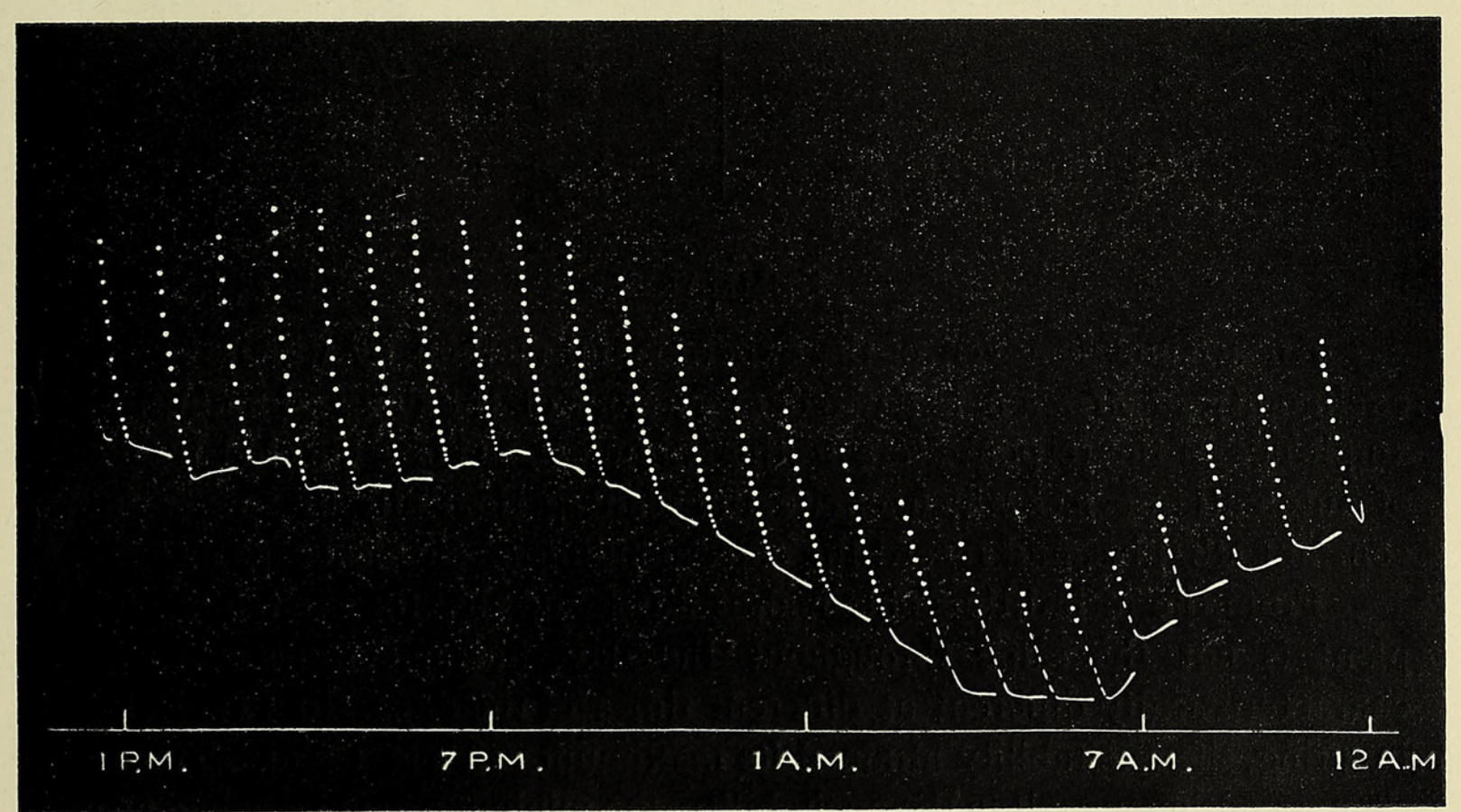

FIG. I7. Diurnal variation of excitability exhibited by summer specimen.

season often rises above $100^{\circ} \mathrm{F}$. or $38^{\circ} \mathrm{C}$. Table II also exhibits, in the case of the summer specimen, the relation between the hours of the day, temperature, and excitability.

An inspection of the record given in Fig. I 7 shows that the amplitude of response was enhanced after $4 \mathrm{p} . \mathrm{m}$. The temperature up to that time was unusually high $\left(38^{\circ} \mathrm{C}\right.$.), and there was in consequence a depression of excitability. After that hour there was a mitigation of heat, the temperature returning towards the optimum. Hence we find that the maximum excitability was attained between the hours 4 and 6 p.m. The minimum temperature at night was higher in the present case than that of the experiment carried out in February; in the former the minimum was $25.5^{\circ} \mathrm{C}$., while in the latter it was $19.5^{\circ} \mathrm{C}$. On account of this difference the night record in summer shows a fall of excitability which is far more gradual than 
that obtained in spring. The excitability is here not totally abolished in the morning, but reaches a minimum about 8 a.m.; the sensitiveness is then gradually enhanced in a staircase manner.

\section{TABLE II.}

Showing the relation between hour of the day, temperature, and excitability. (Summer specimen.)

\begin{tabular}{|c|c|c|c|c|c|}
\hline \multicolumn{2}{|c|}{$\begin{array}{c}\text { Hours of } \\
\text { day. }\end{array}$} & \multicolumn{2}{|c|}{ Temperature. } & \multicolumn{2}{|c|}{$\begin{array}{c}\text { Amplitude of } \\
\text { Response. }\end{array}$} \\
\hline & $\mathrm{m}$. & $3^{8^{\circ}}$ & C. & 22 & mm. \\
\hline 2 &, & $38^{\circ}$ & , & 23 & ", \\
\hline 3 & ," & $38^{\circ}$ & ," & 24.5 & ", \\
\hline 4 & ", & $37^{\circ}$ & , & 28 & ", \\
\hline 5 &, & $35.5^{\circ}$ & , & 29 & ", \\
\hline 6 & ," & $33^{\circ}$ & , & 27 & , \\
\hline 7 & ," & $3^{I^{\circ}}$ & , & 26 & ," \\
\hline 8 & ," & $30^{\circ}$ & ," & 26 & ," \\
\hline 9 & ," & $29^{\circ}$ &, & 25 & , \\
\hline 10 & , , & $27^{\circ}$ & ,, & 24.5 & ," \\
\hline I I & ," & $27^{\circ}$ & ," & 24 & ," \\
\hline I 2 & , , & $26 \cdot 5^{\circ}$ & ," & $22 \cdot 5$ & , \\
\hline
\end{tabular}

$\mid$

Hours of
day.
I a.m.
2 ",
3 ",
4 ",
5
$6 \%$,
$7 \%$,
$8,$,
99,
I0,
I I ",
I $2, "$

Temperature.
$26^{\circ} \mathrm{C}$.
$26^{\circ}, "$
$25.5^{\circ} "$,
$25.5^{\circ}$,
$25.5^{\circ}$,
$26^{\circ}$,
$27^{\circ}$,
$29^{\circ}$,
$30^{\circ}$,
$33^{\circ}$,
$35^{\circ}$,
$37^{\circ}$,

Amplitude of
Response.
2 I.5 mm.
$20 \quad$,
I $8 \cdot 5 \quad "$
I7,
I6,
I5,
I4,
I3,
II,
I6,
I7,
2I,

\section{SUMMARY.}

An account is given of the experimental method by which the motoexcitability of Mimosa is gauged, every hour of the day and night, by the amplitude of the response to a testing stimulus. This is effected by means of automatic devices which excite the plant periodically by an absolutely constant stimulus, and record the corresponding mechanical response.

From the record thus obtained, it was found that the excitability of the plant is not the same throughout the day, but undergoes a variation characteristically different at different times of the day. In a typical case in spring, the excitability attained its maximum value at I p.m. There was then a continuous fall in the excitability, the minimum being reached at nine the following morning. The plant at this time was practically insensitive. The moto-excitability was then gradually enhanced in a staircase manner till it again reached a maximum at I p.m.

Investigations are also described for the determination of the influence of periodically changing external conditions on the diurnal variation of excitability.

The effect of sudden darkness was found to induce a transient depression, followed by revival of excitability. The effect of persistent darkness was to induce a depression.

Exposure to light caused a transient depression, followed by an enhancement of excitability.

Excessive turgor induced a diminished response.

Lowering of temperature induced a depression of excitability, culminating in an abolition of response. The after-effect of excessive cold was a persistent depression of excitability. 
Excitability was enhanced by rising temperature up to an optimum; above this point a depression was induced.

The induced variation of excitability lags behind the inducing cause.

There is a relation between the recurrent changes of external conditions and the diurnal variation of excitability. The periodic variation of light, temperature, and turgor, as well as the phenomenon of lag, are factors which determine the periodic variation of excitability observed in the plant.

Postscript. It should be explained that the term 'moto-excitability' is intended to convey the idea that the observed periodic variation is probably to be attributed in part to variation in the motility of the pulvinus, as well as to variation in the excitability of the leaf. That the latter is the predominant factor appears from the fact that the minimal intensity of stimulus required in the afternoon was found to be only about one-fifth of that in the forenoon.

It is of interest to compare the results here recorded with those of Millardet ('Nouvelles Recherches sur la Périodicité de la Tension chez la Sensitive,' Strasbourg, I 869). 


\section{$2 \mathrm{BHL}$ Biodiversity Heritage Library}

Bose, Jagadis Chandra. 1913. "On diurnal variation of moto-excitability in Mimosa." Annals of botany 27, 759-779.

https://doi.org/10.1093/oxfordjournals.aob.a089486.

View This Item Online: https://www.biodiversitylibrary.org/item/237410

DOI: https://doi.org/10.1093/oxfordjournals.aob.a089486

Permalink: https://www.biodiversitylibrary.org/partpdf/319999

\section{Holding Institution}

Smithsonian Libraries

\section{Sponsored by}

Biodiversity Heritage Library

\section{Copyright \& Reuse}

Copyright Status: Not in copyright. The BHL knows of no copyright restrictions on this item.

This document was created from content at the Biodiversity Heritage Library, the world's largest open access digital library for biodiversity literature and archives. Visit BHL at https://www.biodiversitylibrary.org. 